\title{
Circulating tumor DNA analysis as a real-time method for monitoring tumor burden in melanoma patients undergoing treatment with immune checkpoint blockade
}

\author{
Evan J Lipson ${ }^{1 *}$, Victor E Velculescu ${ }^{1}$, Theresa S Pritchard², Mark Sausen ${ }^{4}$, Drew M Pardoll',
}

Suzanne L Topalian ${ }^{2}$ and Luis A Diaz Jr. ${ }^{1,3}$

\begin{abstract}
Background: Assessment of therapeutic activity of drugs blocking immune checkpoints such as CTLA-4 and PD-1/PD-L1 can be challenging, as tumors may seem to enlarge or appear anew before regressing, due to intratumoral inflammation. We assessed whether circulating tumor DNA (ctDNA) levels could serve as an early indicator of true changes in tumor burden in patients undergoing treatment with these agents.

Findings: Tumors from 12 patients with metastatic melanoma undergoing treatment with checkpoint blocking drugs were analyzed for the presence of hotspot somatic mutations in BRAF, CKIT, NRAS, and TERT. Plasma was collected serially from each patient and levels of ctDNA were compared with radiologic and clinical outcomes.

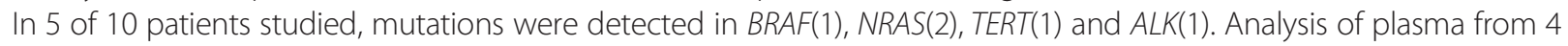
of 5 patients identified mutations identical to those found in tumor specimens. Plasma ctDNA levels ranged from undetectable $(<0.01 \%)$ to $5.5 \%$ of total circulating cell-free DNA. In 3 patients, increasing ctDNA levels correlated with progressive disease assessed by radiography. In one patient, ctDNA levels increased after undergoing a needle biopsy of a tumor deposit. In another patient, ctDNA levels increased initially as lymphadenopathy progressed by examination, but then became undetectable 3 weeks prior to clinical improvement.

Conclusions: Levels of ctDNA correlated with clinical and radiologic outcomes, and, in one case, preceded eventual tumor regression. Further prospective analysis is required to assess the utility of ctDNA as an early biomarker of clinical outcomes in patients receiving immune checkpoint blocking drugs.
\end{abstract}

Keywords: Circulating tumor DNA, Immunotherapy, Checkpoint blockade, Anti-PD-1, Ipilimumab, Biomarker

\section{Findings}

\section{Background}

Our group and others have previously reported that circulating tumor DNA (ctDNA) can be detected in the plasma of patients with advanced melanoma and other malignancies [1-6]. Furthermore, levels of ctDNA can correlate with changes in tumor burden in response to surgery or chemotherapy $[7,8]$. The current study tested the hypothesis that ctDNA levels in the plasma of patients with

\footnotetext{
* Correspondence: evanlipson@jhmi.edu

'Department of Oncology, Johns Hopkins University School of Medicine and Sidney Kimmel Comprehensive Cancer Center, Baltimore, MD, USA

Full list of author information is available at the end of the article
}

metastatic melanoma could serve as early biomarkers of therapeutic responses to immune checkpoint blockade therapy.

Monoclonal antibodies blocking immune checkpoint molecules such as Programmed Death-1 (PD-1; nivolumab and pembrolizumab), PD-ligand 1 (PD-L1; BMS936559, MPDL3280A, and MEDI4736), and Cytotoxic T lymphocyte-associated Antigen 4 (CTLA-4; ipilimumab), have mechanisms of action which differ significantly from standard cytotoxic therapies [9]. This creates challenges for assessing therapeutic activity. Checkpoint blocking
C Biomed Central

(c) 2014 Lipson et al.; licensee BioMed Central. This is an Open Access article distributed under the terms of the Creative Commons Attribution License (http://creativecommons.org/licenses/by/4.0), which permits unrestricted use, distribution, and reproduction in any medium, provided the original work is properly credited. The Creative Commons Public Domain Dedication waiver (http://creativecommons.org/publicdomain/zero/1.0/) applies to the data made available in this article, unless otherwise stated. 
drugs act directly on the immune system, rather than on the tumor, and the kinetics of tumor regression may be delayed $[10,11]$. In some cases, tumors assessed using conventional CT imaging criteria (RECIST; [12] appear to enlarge during therapy before regressing. In other patients, new tumors appear on therapy which later regress. Some tumors remain stable in size for a prolonged period of time, even after treatment has been stopped [13-16]. It has been proposed that apparent tumor progression may, in some cases, reflect intratumoral inflammation rather than actual tumor growth [17]. Non-invasive indicators of changes in tumor burden could provide early information about therapeutic outcomes and avoid unnecessary exposure to potentially serious immune-related toxicities in patients with true disease progression [18].

\section{Methods}

Twelve patients with metastatic melanoma who were scheduled to receive treatment with an immune checkpoint blocking drug at our institution, including ipilimumab (anti-CTLA-4) or BMS-936559 (anti-PD-L1) (NCT00729664, Ref. [14]), provided informed consent to participate in this IRB-approved study. Archived formalin-fixed, paraffin-embedded tumor specimens were analyzed for common, recurrent somatic sequence mutations in BRAF, cKIT, NRAS and TERT [19] using standardized pyrosequencing, melting curve analysis, or Sanger sequencing techniques, as previously described [20,21]. Methodological details for the 5 patients in whom a tumor mutation was detected are included in Additional file 1: Table S1. In one case, whole exome sequencing was performed to identify a unique tumor-specific mutation that could be used to quantify ctDNA in plasma. Sample library construction, exome capture, next generation sequencing, and bioinformatic analyses were performed at Personal Genome Diagnostics (Baltimore, MD). Genomic DNA, obtained from circulating leukocytes, was fragmented and used for Illumina TruSeq library construction (Illumina, San Diego, CA). Exonic regions were captured in solution using the Agilent SureSelect $50 \mathrm{Mb}$ kit (version 4) according to the manufacturer's instructions (Agilent, Santa Clara, CA). Paired-end sequencing, resulting in 100 bases from each end of the fragments, was performed using a HiSeq 2000 Genome Analyzer System (Illumina, San Diego, CA). The sequences were aligned to the human genome reference sequence (hg18) using the Eland algorithm of CASAVA 1.7 software (Illumina, San Diego, CA). The chastity filter of the BaseCall software of Illumina was used to select sequence reads for subsequent analysis. The ELANDv2 algorithm of CASAVA 1.7 software (Illumina, San Diego, CA) was then applied to identify point mutations and small insertions and deletions. Potential somatic mutations were filtered and visually inspected as described previously [22,23].

Blood was collected in $\mathrm{K}_{2}$ EDTA collection vials from each patient prior to therapy, and then at approximately 24 week intervals during treatment. Within 3 hours of collection, samples were centrifuged at $810 \mathrm{~g}$ for ten minutes at room temperature. In a sterile biosafety cabinet, plasma was pooled and aliquoted. Samples were centrifuged at $18,000 \mathrm{~g}$ for ten minutes at room temperature. The supernatant was transferred to cryovials and immediately stored

Table 1 Tumor-specific mutation analysis of 10 melanoma tumor specimens

\begin{tabular}{|c|c|c|c|c|c|c|c|}
\hline $\mathrm{ID}^{\mathrm{a}}$ & BRAF & CKIT & NRAS & Other & Therapy & Radiographic response & $\begin{array}{l}\text { ctDNA level } \\
\text { analyzed? }\end{array}$ \\
\hline \multirow[t]{2}{*}{01} & \multirow[t]{2}{*}{ WT } & \multirow[t]{2}{*}{ WT } & \multirow[t]{2}{*}{ WT } & Chr5: 1,295,228-9 & \multirow[t]{2}{*}{ ipilimumab } & \multirow[t]{2}{*}{ Immune-related PR } & \multirow[t]{2}{*}{$\mathrm{Y}$} \\
\hline & & & & $\mathrm{GG}>\mathrm{AA}(\mathrm{TERT})^{\mathrm{b}}$ & & & \\
\hline 03 & $1799 \mathrm{~T}>\mathrm{A}$ & WT & NT & NT & BMS-936559 & PD & Y \\
\hline 05 & WT & WT & WT & NT & ipilimumab & PD & $N$ \\
\hline 06 & WT & WT & WT & NT & BMS-936559 & PD & $\mathrm{N}$ \\
\hline 07 & WT & WT & WT & NT & ipilimumab & PD & $N$ \\
\hline 08 & WT & WT & $182 A>G$ & NT & BMS-936559 & PD & Y \\
\hline 09 & WT & WT & WT & NT & BMS-936559 & PD & $N$ \\
\hline 10 & WT & WT & $181 C>A$ & NT & ipilimumab & PD & Y \\
\hline \multirow[t]{2}{*}{11} & \multirow[t]{2}{*}{ WT } & \multirow[t]{2}{*}{ WT } & \multirow[t]{2}{*}{ WT } & Chr2: 29,551,215 & \multirow[t]{2}{*}{ ipilimumab } & \multirow[t]{2}{*}{$C R$} & \multirow[t]{2}{*}{ N } \\
\hline & & & & $\mathrm{C}>\mathrm{T}(\mathrm{ALK})^{\mathrm{b}}$ & & & \\
\hline 12 & WT & WT & $N T^{c}$ & NT & ipilimumab & PD & $N$ \\
\hline
\end{tabular}

Archived formalin-fixed, paraffin-embedded tumor specimens were analyzed for common, recurrent somatic sequence mutations in BRAF, CKIT, NRAS and TERT [19] using standardized pyrosequencing, melting curve analysis, or Sanger sequencing techniques, as previously described (Wood et. al., Science. 2007 Nov 16;318 (5853):1 108-13. and Parsons et. al., Science. 2008 Sep 26;321(5897):1807-12.). No mutation was detected in 5 of 10 patients. Previously reported mutations associated with melanoma (BRAF, NRAS, TERT) were found in 4 patients. For one subject (\#11) whose tumor was found to be wild type for each of the above genes, whole exome sequencing analysis of tumor and normal samples was employed to identify tumor-specific (somatic) sequence and copy number alterations. (WT, wild type; NT, not tested; PR, partial response; PD, progressive disease; CR, complete response; ${ }^{a}$ patient ID numbers are not sequential as 2 patients who died due to disease progression prior to completing their courses of therapy are not included in Table $1 ;{ }^{b}$ genomic position, hg19; ${ }^{c}$ No PCR amplified product was obtained after repeated attempts). 
at $-80 \mathrm{C}$. Buffy coat was collected from each EDTA tube and immediately stored at $-80 \mathrm{C}$. DNA was extracted using the QIAamp Circulating Nucleic Acid Kit (Qiagen, Valencia, CA). BEAMing technology (Beads, Emulsification, Amplification and Magnetics; Inostics, Hamburg, Germany) was used to detect and quantify circulating melanoma-derived DNA [7,24]. In one case, a custom
PCR and next-generation sequencing approach was required due to difficulty in generating a BEAMing probe specific to the TERT promoter locus, due to high GC content. Briefly, DNA was partitioned into reactions each containing approximately 1,000 genomic equivalents (GE), from which a mutation was called if present in at least two independent PCR and next-generation sequencing
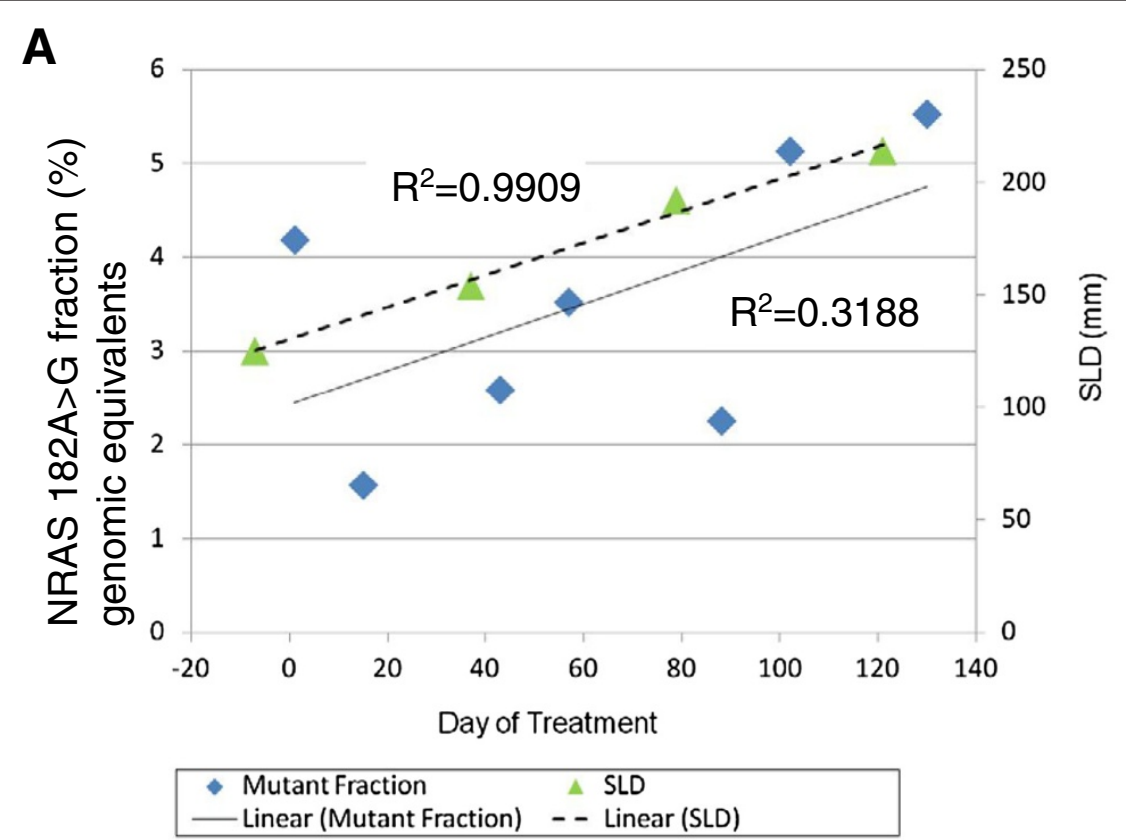

B

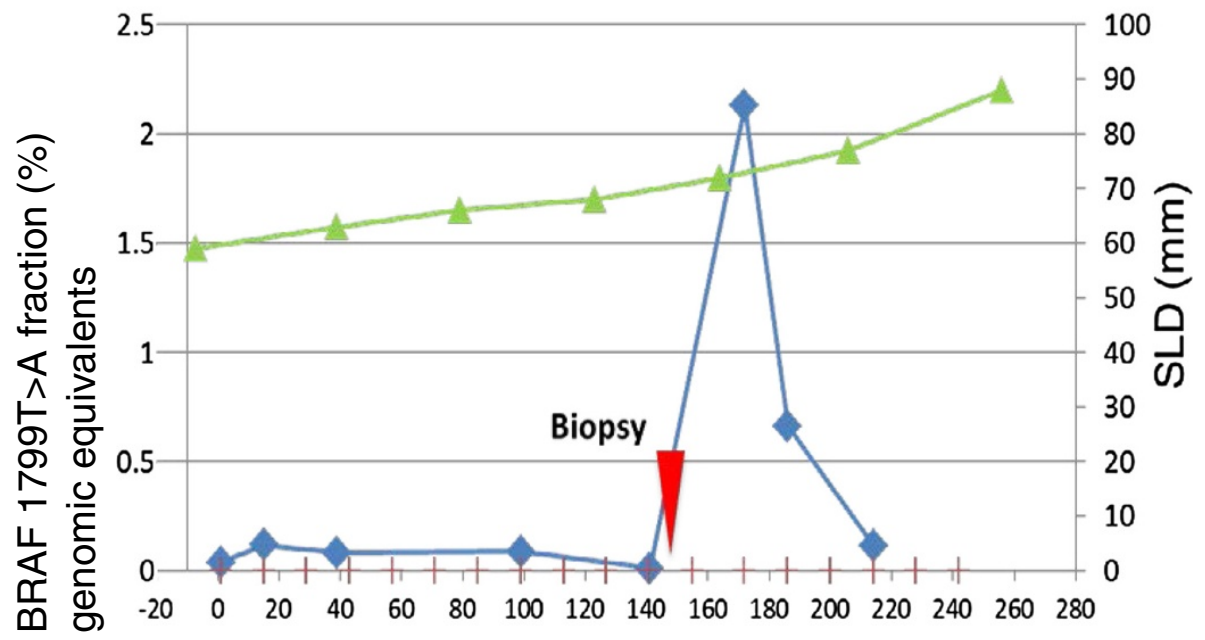

Day of Treatment

\section{$\leftarrow$ Mutant Fraction $\quad-$ SLD $\quad+$ Dose}

Figure 1 Correlation of ctDNA measurements with clinical course. A) Increasing levels of ctDNA (NRAS A182G) correlate with progressive disease assessed by radiography in patient \#08, a 52-year-old man with metastatic melanoma who received BMS-936559 (anti-PD-L1). B) Levels of ctDNA (BRAF V600E) in patient \#03, a 69-year-old woman with metastatic melanoma who received BMS-936559, increased substantially after a needle biopsy of a lower extremity soft tissue metastasis on treatment day 155 (red arrow). SLD, sum of longest tumor diameters. 


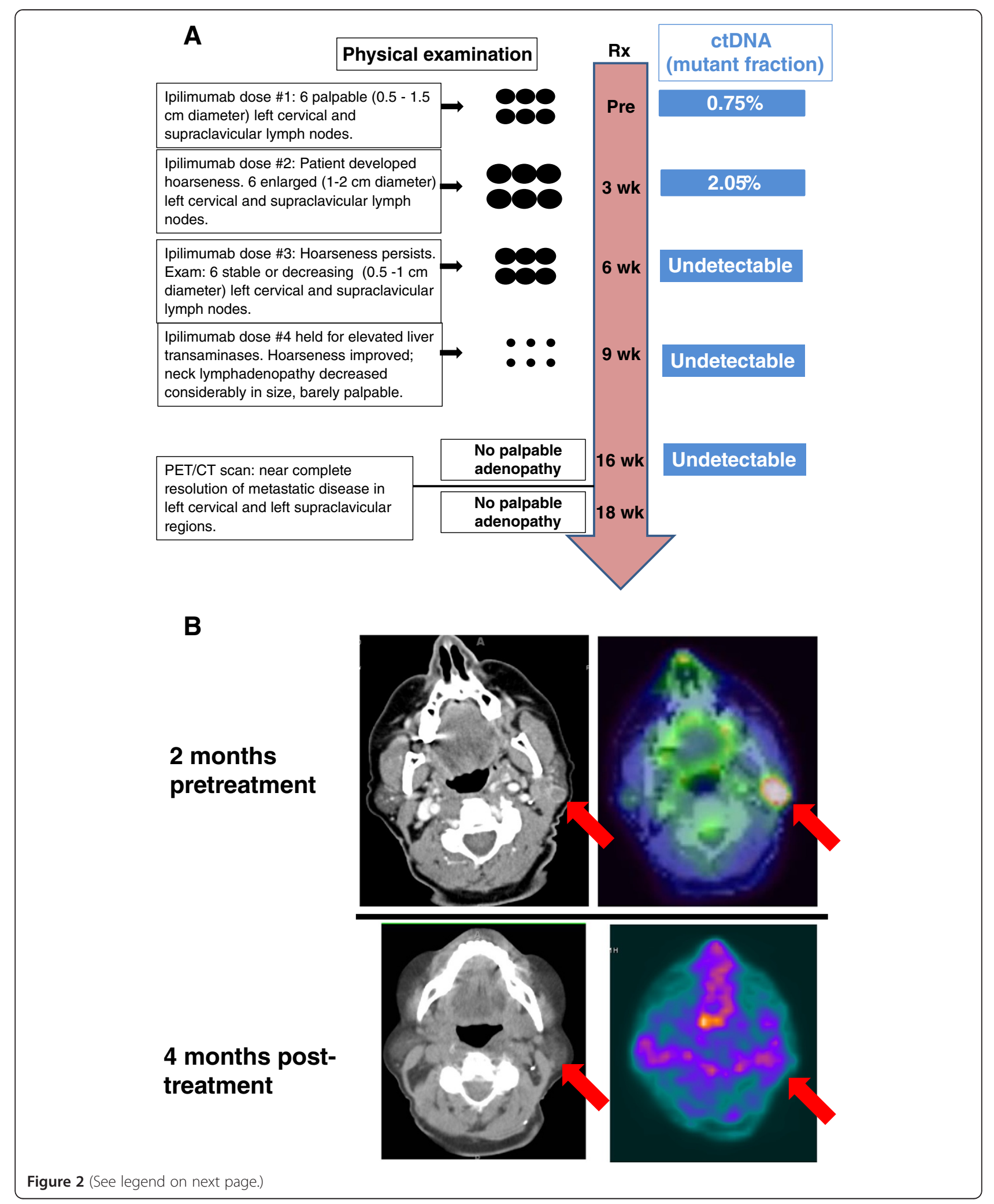


(See figure on previous page.)

Figure 2 Clinical course and ctDNA measurements for patient \#01, a 68-year-old woman with biopsy-proven unresectable melanoma of the left neck and left supraclavicular regions. She received ipilimumab as first-line therapy, to which she had an "immune-related" response. A) Treatment timeline. Ipilimumab (anti-CTLA-4, 3 mg/kg) was administered intravenously every 3 weeks for 3 doses. ctDNA levels (TERTmut) increased initially as metastatic lymph nodes enlarged on physical examination (week 3), but ctDNA became undetectable at week 6 even though metastatic lymph nodes were still palpable. Significant disease regression was noted clinically 3 weeks later and complete disease resolution was demonstrated on CT and FDG-PET scans performed 4 months after treatment initiation. B) CT and FDG-PET images demonstrating the resolution of palpable cervical lymphadenopathy after administration of ipilimumab.

reactions, as previously described [25]. ctDNA fractions were quantified by taking the total mutant observations divided by the total GE analyzed. The lower limit of sensitivity for this assay was dependent on the total GE analyzed, and ranged from 1,603 to 15,308, yielding a sensitivity of $>0.1 \%$. Results were correlated with radiologic and clinical outcomes.

\section{Results}

Two patients died due to disease progression prior to completing their courses of therapy. Of ten evaluable patients, one demonstrated a mutation in BRAF (1799T > A (V600E)), none in $c K I T$ and two in NRAS $(182 \mathrm{~A}>\mathrm{G}$ (Q61R), 181C > A (Q61K)). TERT mutation testing was performed on 2 patients whose tumors were wild-type for the 3 genes listed above, and one demonstrated a mutation (Chr5: 1,295,228-9;GG > AA). In another patient, whole exome sequencing analysis of tumor and normal samples revealed a mutation in $A L K$ (Chr2: 29,551,215; $\mathrm{C}>\mathrm{T}$ ); plasma DNA levels were not analyzed for this patient (Table 1).

Analysis of plasma from 4 patients identified mutations identical to those found in tumor specimens (BRAF, NRAS, TERT). Plasma ctDNA levels measured as a fraction of total GE in cell-free DNA ranged from below the detection limits of the PCR/next-generation sequencing assay $(<0.1 \%)$ or the BEAMing assay $(<0.01 \%)$ to $5.5 \%$ of total circulating DNA.

Increasing levels of tumor-derived ctDNA were seen in conjunction with progressive disease assessed by radiography in three patients. In one patient, ctDNA levels increased substantially after a needle biopsy of a tumor deposit was performed, validating the sensitivity of these methods (Figure 1).

In one patient who experienced an "immune-related" response to ipilimumab therapy - clinical disease progression early in the treatment course, followed by a sustained response to treatment - plasma levels of tumor-derived DNA became undetectable several weeks prior to clinical tumor regression (Figure 2).

\section{Discussion}

Clinical management of patients undergoing therapy with immune checkpoint blocking drugs can be challenging. Radiographic changes seen on conventional CT scans can be misleading, as tumors may appear to enlarge or appear anew before later regressing. Furthermore, prolonged disease stabilization may contribute to overall survival benefits. Although serum levels of CEA, CA19-9 and PSA can be used as surrogate markers of tumor burden changes in colon, pancreas and prostate cancer, many cancers such as melanoma have no validated tumor marker. However, genetic alterations contained in human cancers, including gene deletions or amplifications, point mutations and chromosomal rearrangements, can distinguish cell-free tumor DNA from normal DNA and can serve as personalized biomarkers of disease in patients with advanced melanoma and other malignancies.

Approximately $90 \%$ of melanomas harbor a point mutation in BRAF, NRAS or $c K I T$ [26]. Likewise, mutations in the TERT promoter have been reported in approximately $40-70 \%$ of melanoma tumors $[19,27]$. These highfrequency mutations could be used to track ctDNA levels in a majority of patients with metastatic melanoma. For patients with other tumor types with more diverse and/or private mutations, whole exome sequencing may be required in order to identify a genetic alteration suitable for detection in the circulation.

In this pilot study, changes in ctDNA levels correlated with physical examination and radiologic outcomes in patients receiving checkpoint blockade agents. In one case, decreasing ctDNA levels preceded eventual clinical and radiographic tumor regression. Thus, ctDNA levels may serve as an early biomarker, reflecting tumor burden changes more quickly than those detected using CT radiography. Although these findings require further prospective analysis and validation in larger numbers of patients, an easily-measured, accurate, plasma-based marker of disease such as ctDNA would potentially change patient management in several settings. First, decreasing levels of ctDNA detected during the appearance of clinical or radiographic disease progression might aid in the early identification of patients whose tumors will soon respond to treatment and, therefore, should continue on therapy. Second, ctDNA levels that are rising in the period between radiologic evaluations might prompt the clinician to consider early radiologic restaging, since rising ctDNA could indicate true disease progression, or tumor lysis preceding regression. Third, in patients whose cancers recur after a prolonged period of regression off therapy [13], ctDNA 
may serve as an early indicator of tumor growth and prompt a re-initiation of therapy. Lastly, in early-stage patients who have undergone surgical resection of disease, plasma evidence of residual disease may influence recommendations for adjuvant therapy $[28,29]$.

The initial increase in levels of ctDNA in patient \#01 potentially supports the theory that apparent tumor progression may, in some cases, reflect intratumoral inflammation and immune-mediated tumor destruction, rather than actual tumor growth [17]. In analogous fashion, an acute, destructive event within a tumor deposit in patient \#03 (i.e., a physical disruption with a biopsy needle) appeared to significantly increase ctDNA levels. One question that stems from this observation concerns the possible seeding of distant disease by disruption of a melanoma deposit. However, several studies have demonstrated that surgical transection of a primary melanoma at initial biopsy does not affect patient survival, regardless of biopsy technique employed [30-32].

Our study is the first to demonstrate that changes in ctDNA may be predictive of the anti-tumor activity of immune checkpoint blocking drugs. Further study involving larger numbers of patients is needed to assess the utility of ctDNA levels in detecting fluctuations in tumor burden prior to clinically or radiographically measureable changes in patients receiving these agents.

\section{Additional file}

Additional file 1: Table S1. Methods used for mutational analysis of tumor tissue for the 5 patients in our study in whom a genetic mutation was detected.

\section{Abbreviations \\ BEAM: Beads, Emulsification, Amplification and Magnetics; ctDNA: Circulating tumor DNA; CR: Complete response; CT: Computed tomography; CTLA-4: Cytotoxic T Lymphocyte Antigen-4; GE: Genomic equivalents; PR: Partial response; PCR: Polymerase chain reaction; PET: Positron emission tomography; PD-L1: Programmed Death Ligand-1; PD-1: Programmed Death-1; PD: Progressive disease; SLD: Sum of Longest Diameters; SD: Stable disease.}

\section{Competing interests}

$L A D$ and VEV are co-founders of Personal Genome Diagnostics and are members of its Scientific Advisory Board and Board of Directors. LAD and VEV own Personal Genome Diagnostics stock, which is subject to certain restrictions under University policy. The terms of these arrangements are managed by the Johns Hopkins University in accordance with its conflict-of-interest policies. MS is a full-time employee of Personal Genome Diagnostics.

\section{Authors' contributions}

EJL contributed to the conception and coordination of the manuscript, data acquisition, figure design, drafting and final revision of the manuscript. VEV contributed to the conception of the project, design of the experiments, and revision of the manuscript. TSP contributed to specimen processing and revision of the manuscript. MS analyzed data and contributed to the manuscript. DMP contributed to the conception and design of the study, analysis of data, and revision of the manuscript. SLT contributed to the conception and design of the study, analysis of data, and revision of the manuscript. LAD contributed to the conception of the project, design of the experiments, and revision of the manuscript. All authors read and approved the final manuscript.

\section{Acknowledgments}

Grant support: Ludwig Center for Cancer Genetics and Therapeutics at Johns Hopkins; Melanoma Research Alliance; and NIH grant CA121113.

\section{Author details}

${ }^{1}$ Department of Oncology, Johns Hopkins University School of Medicine and Sidney Kimmel Comprehensive Cancer Center, Baltimore, MD, USA.

${ }^{2}$ Department of Surgery, Johns Hopkins University School of Medicine and Sidney Kimmel Comprehensive Cancer Center, Baltimore, MD, USA. ${ }^{3}$ Ludwig Center for Cancer Genetics and Therapeutics and the Swim Across America Laboratory, Johns Hopkins University School of Medicine and Sidney Kimmel Comprehensive Cancer Center, Baltimore, MD, USA. ${ }^{4}$ Personal Genome Diagnostics, Baltimore, MD, USA.

Received: 16 August 2014 Accepted: 27 November 2014

Published online: 16 December 2014

\section{References}

1. Bettegowda C, Sausen M, Leary RJ, Kinde I, Wang Y, Agrawal N, Bartlett BR, Wang H, Luber B, Alani RM, Antonarakis ES, Azad NS, Bardelli A, Brem H, Cameron JL, Lee CC, Fecher LA, Gallia GL, Gibbs P, Le D, Giuntoli RL, Goggins M, Hogarty MD, Holdhoff M, Hong SM, Jiao Y, Juhl HH, Kim JJ, Siravegna G, Laheru D, et al: Detection of circulating tumor DNA in early- and late-stage human malignancies. Sci Transl Med 2014, 6:224ra24.

2. Leary RJ, Sausen M, Kinde I, Papadopoulos N, Carpten JD, Craig D, O'Shaughnessy J, Kinzler KW, Parmigiani G, Vogelstein B, Diaz LA Jr, Velculescu VE: Detection of chromosomal alterations in the circulation of cancer patients with whole-genome sequencing. Sci Transl Med 2012, 4:162ra154.

3. Newman AM, Bratman SV, To J, Wynne JF, Eclov NC, Modlin LA, Liu CL, Neal JW, Wakelee HA, Merritt RE, Shrager JB, Loo BW Jr, Alizadeh AA, Diehn M: An ultrasensitive method for quantitating circulating tumor DNA with broad patient coverage. Nat Med 2014, 20:548-554.

4. Forshew T, Murtaza M, Parkinson C, Gale D, Tsui DW, Kaper F, Dawson SJ, Piskorz AM, Jimenez-Linan M, Bentley D, Hadfield J, May AP, Caldas C, Brenton JD, Rosenfeld N: Noninvasive identification and monitoring of cancer mutations by targeted deep sequencing of plasma DNA. Sci Trans/ Med 2012, 4:136ra68.

5. Diehl F, Li M, Dressman D, He Y, Shen D, Szabo S, Diaz LA Jr, Goodman SN, David KA, Juhl H, Kinzler KW, Vogelstein B: Detection and quantification of mutations in the plasma of patients with colorectal tumors. Proc Natl Acad Sci U S A 2005, 102:16368-16373.

6. Dawson SJ, Tsui DW, Murtaza M, Biggs H, Rueda OM, Chin SF, Dunning MJ, Gale D, Forshew T, Mahler-Araujo B, Rajan S, Humphray S, Becq J, Halsall D, Wallis M, Bentley D, Caldas C, Rosenfeld N: Analysis of circulating tumor DNA to monitor metastatic breast cancer. N Engl J Med 2013, 368:1199-1209.

7. Diehl F, Schmidt K, Choti MA, Romans K, Goodman S, Li M, Thornton K, Agrawal N, Sokoll L, Szabo SA, Kinzler KW, Vogelstein B, Diaz LA Jr: Circulating mutant DNA to assess tumor dynamics. Nat Med 2008, 14:985-990.

8. Momtaz P, Gaskell AA, Merghoub T, Viale A, Chapman PB: Correlation of tumor-derived circulating cell free DNA (cfDNA) measured by digital PCR (DigPCR) with tumor burden measured radiographically in patients (pts) with BRAFV600Emutated melanoma (mel) treated with RAF inhibitor (RAFi) and/or ipilimumab (Ipi). ASCO Meeting Abstracts 2014, 32:9085.

9. Pardoll DM: The blockade of immune checkpoints in cancer immunotherapy. Nat Rev Cancer 2012, 12:252-264.

10. Wolchok JD, Hoos A, O'Day S, Weber JS, Hamid O, Lebbe C, Maio M, Binder M, Bohnsack O, Nichol G, Humphrey R, Hodi FS: Guidelines for the evaluation of immune therapy activity in solid tumors: immune-related response criteria. Clin Cancer Res 2009, 15:7412-7420.

11. Saenger YM, Wolchok JD: The heterogeneity of the kinetics of response to ipilimumab in metastatic melanoma: patient cases. Cancer Immun 2008, 8:1.

12. Eisenhauer EA, Therasse P, Bogaerts J, Schwartz LH, Sargent D, Ford R, Dancey J, Arbuck S, Gwyther S, Mooney M, Rubinstein L, Shankar L, Dodd L, Kaplan R, Lacombe D, Verweij J: New response evaluation criteria in solid tumours: revised RECIST guideline (version 1.1). Eur J Cancer 2009, 45:228-247.

13. Lipson EJ, Sharfman WH, Drake CG, Wollner I, Taube JM, Anders RA, Xu H, Yao S, Pons A, Chen L, Pardoll DM, Brahmer JR, Topalian SL: Durable cancer 
regression off-treatment and effective reinduction therapy with an anti-PD-1 antibody. Clin Cancer Res 2013, 19:462-468.

14. Brahmer JR, Tykodi SS, Chow LQ, Hwu WJ, Topalian SL, Hwu P, Drake CG Camacho LH, Kauh J, Odunsi K, Pitot HC, Hamid O, Bhatia S, Martins R, Eaton K, Chen S, Salay TM, Alaparthy S, Grosso JF, Korman AJ, Parker SM, Agrawal S, Goldberg SM, Pardoll DM, Gupta A, Wigginton JM: Safety and activity of anti-PD-L1 antibody in patients with advanced cancer. N Engl J Med 2012, 366:2455-2465.

15. Hodi FS, O'Day SJ, McDermott DF, Weber RW, Sosman JA, Haanen JB, Gonzalez R, Robert C, Schadendorf D, Hassel JC, Akerley W, van den Eertwegh AJ, Lutzky J, Lorigan P, Vaubel JM, Linette GP, Hogg D, Ottensmeier CH, Lebbe C, Peschel C, Quirt I, Clark Jl, Wolchok JD, Weber JS, Tian J, Yellin MJ, Nichol GM, Hoos A, Urba WJ: Improved survival with ipilimumab in patients with metastatic melanoma. N Engl J Med 2010, 363:711-723.

16. Topalian SL, Sznol M, McDermott DF, Kluger HM, Carvajal RD, Sharfman WH, Brahmer JR, Lawrence DP, Atkins MB, Powderly JD, Leming PD, Lipson EJ, Puzanov I, Smith DC, Taube JM, Wigginton JM, Kollia GD, Gupta A, Pardoll DM, Sosman JA, Hodi FS: Survival, durable tumor remission, and long-term safety in patients with advanced melanoma receiving nivolumab. J Clin Oncol 2014, 32:1020-1030.

17. Ribas A, Chmielowski B, Glaspy JA: Do we need a different set of response assessment criteria for tumor immunotherapy? Clin Cancer Res 2009, $15: 7116-7118$

18. Weber JS, Kahler KC, Hauschild A: Management of immune-related adverse events and kinetics of response with ipilimumab. J Clin Oncol 2012, 30:2691-2697.

19. Huang FW, Hodis E, Xu MJ, Kryukov GV, Chin L, Garraway LA: Highly recurrent TERT promoter mutations in human melanoma. Science 2013, 339:957-959.

20. Wood LD, Parsons DW, Jones S, Lin J, Sjoblom T, Leary RJ, Shen D, Boca SM, Barber T, Ptak J, Silliman N, Szabo S, Dezso Z, Ustyanksky V, Nikolskaya T, Nikolsky Y, Karchin R, Wilson PA, Kaminker JS, Zhang Z, Croshaw R, Willis J, Dawson D, Shipitsin M, Willson JK, Sukumar S, Polyak K, Park BH, Pethiyagoda CL, Pant PV, et al: The genomic landscapes of human breast and colorectal cancers. Science 2007, 318:1108-1113.

21. Parsons DW, Jones $S$, Zhang $X$, Lin JC, Leary RJ, Angenendt P, Mankoo P, Carter H, Siu IM, Gallia GL, Olivi A, McLendon R, Rasheed BA, Keir S, Nikolskaya T, Nikolsky Y, Busam DA, Tekleab H, Diaz LA Jr, Hartigan J, Smith DR, Strausberg RL, Marie SK, Shinjo SM, Yan H, Riggins GJ, Bigner DD, Karchin R, Papadopoulos N, Parmigiani G, Vogelstein B, Velculescu VE, Kinzler KW: An integrated genomic analysis of human glioblastoma multiforme. Science 2008, 321:1807-1812.

22. Jones $S$, Zhang $X$, Parsons DW, Lin JC, Leary RJ, Angenendt P, Mankoo P, Carter H, Kamiyama H, Jimeno A, Hong SM, Fu B, Lin MT, Calhoun ES, Kamiyama M, Walter K, Nikolskaya T, Nikolsky Y, Hartigan J, Smith DR, Hidalgo M, Leach SD, Klein AP, Jaffee EM, Goggins M, Maitra A, lacobuzioDonahue C, Eshleman JR, Kern SE, Hruban RH, Karchin R, Papadopoulos N, Parmigiani G, Vogelstein B, Velculescu VE, Kinzler KW: Core signaling pathways in human pancreatic cancers revealed by global genomic analyses. Science 2008, 321:1801-1806.

23. Sausen M, Leary RJ, Jones S, Wu J, Reynolds CP, Liu X, Blackford A, Parmigiani G, Diaz LA Jr, Papadopoulos N, Vogelstein B, Kinzler KW, Velculescu VE, Hogarty MD: Integrated genomic analyses identify ARID1A and ARID1B alterations in the childhood cancer neuroblastoma. Nat Genet 2013, 45:12-17.

24. Diehl F, Li M, He Y, Kinzler KW, Vogelstein B, Dressman D: BEAMing: singlemolecule PCR on microparticles in water-in-oil emulsions. Nat Methods 2006, 3:551-559.

25. Kinde I, WU J, Papadopoulos N, Kinzler KW, Vogelstein B: Detection and quantification of rare mutations with massively parallel sequencing. Proc Natl Acad Sci U S A 2011, 108:9530-9535.

26. Hodis E, Watson I, Kryukov G, Arold S, Imielinski M, Theurillat J, Nickerson E, Auclair D, Li L, Place C, DiCara D, Ramos A, Lawrence M, Cibulskis K, Sivachenko A, Voet D, Saksena G, Stransky N, Onofrio R, Winckler W, Ardlie K, Wagle N, Wargo J, Chong K, Morton D, Stemke-Hale K, Chen G, Noble M, Meyerson M, Ladbury J, Davies M, Gershenwald J, Wagner S, Hoon DB, Schadendorf D, Lander E, Gabriel S, Getz G, Garraway L, Chin L: A Landscape of Driver Mutations in Melanoma. Cell 2012, 150:251-263.

27. Griewank KG, Murali R, Puig-Butille JA, Schilling B, Livingstone E, Potrony M, Carrera C, Schimming T, Moller I, Schwamborn M, Sucker A, Hillen U, Badenas C, Malvehy J, Zimmer L, Scherag A, Puig S, Schadendorf D: TERT promoter mutation status as an independent prognostic factor in cutaneous melanoma. J Natl Cancer Inst 2014, 106:dju246.
28. Diaz LA, Bardelli A: Liquid Biopsies: Genotyping Circulating Tumor DNA. J Clin Oncol 2014, 32:579-586.

29. Haber DA, Velculescu VE: Blood-based analyses of cancer: circulating tumor cells and circulating tumor DNA. Cancer Discov 2014, 4:650-661.

30. Mir M, Chan CS, Khan F, Krishnan B, Orengo I, Rosen T: The rate of melanoma transection with various biopsy techniques and the influence of tumor transection on patient survival. J Am Acad Dermatol 2013, 68:452-458.

31. Martires KJ, Nandi T, Honda K, Cooper KD, Bordeaux JS: Prognosis of patients with transected melanomas. Dermatol Surg 2013, 39:605-615.

32. Mills JK, White I, Diggs B, Fortino J, Vetto JT: Effect of biopsy type on outcomes in the treatment of primary cutaneous melanoma. Am J Surg 2013, 205:585-590.

doi:10.1186/s40425-014-0042-0

Cite this article as: Lipson et al:: Circulating tumor DNA analysis as a real-time method for monitoring tumor burden in melanoma patients undergoing treatment with immune checkpoint blockade. Journal for ImmunoTherapy of Cancer 2014 2:42.

\section{Submit your next manuscript to BioMed Central and take full advantage of:}

- Convenient online submission

- Thorough peer review

- No space constraints or color figure charges

- Immediate publication on acceptance

- Inclusion in PubMed, CAS, Scopus and Google Scholar

- Research which is freely available for redistribution 